\title{
Recobrimentos brilhantes obtidos por impressão jato de tinta: Influência da natureza do esmalte base
}

\author{
C. Blanco Sánchez \\ Fritta, S.L.U. Ctra. CV20 km 8, Onda, Catellón, Espanha
}

\begin{abstract}
Resumo:
Nos últimos anos, as tintas para impressão jato de tinta utilizadas na indústria cerâmica evoluíram muito e passaram de tintas pigmentadas, necessárias para a decoração cromática das placas cerâmicas, a tintas de efeito, utilizadas para modificar suas propriedades superficiais, sejam mecânicas, químicas ou estéticas. Em todos os casos as tintas não contêm pigmentos cerâmicos, mas são suspensões de outros materiais de natureza inorgânica que, durante a queima, geram os diversos efeitos: brilho, mate, reativo (camaleão), etc. A tecnologia jato de tinta é então utilizada somente como meio de deposição e a maior dificuldade consiste em selecionar e otimizar a composição e espessura das diversas camadas que são aplicadas. Neste trabalho foi estudada a variação de brilho de recobrimentos brilhantes obtidos pela aplicação por jato de tinta de efeito, sobre placas cerâmicas cruas com esmaltes de base de diferentes naturezas, seguida de posterior queima. Ao correlacionar esta propriedade com a microestrutura dos recobrimentos obtidos comprovou-se que esta depende da espessura efetiva do recobrimento. Esta espessura é determinada pela interação entre o material depositado e os componentes do esmalte base.
\end{abstract}

Palavras-chave: Esmalte base; Impressão jato de tinta; Tintas de efeito.

\section{Introdução}

A decoração de placas cerâmicas por impressão digital (jato de tinta) aumentou consideravelmente as possibilidades de decoração desde que foram desenvolvidas as denominadas 'tintas de efeito', entre elas as 'tintas brilhantes' que definem zonas na peça com brilho, quando aplicadas sobre esmaltes mate [1].

As tintas brilhantes devem ser capazes de gerar vidrados lisos nos quais a reflexão da luz incidente seja majoritariamente especular, minimizando a contribuição da luz difusa. O fator mais importante que afeta o brilho de uma superfície é a rugosidade, existindo uma relação direta entre brilho e rugosidade superficial. Nas pinturas são utilizadas cargas inorgânicas para modificar a rugosidade superficial e controlar o brilho. Tais cargas originam protuberâncias sobre a superfície, que aumentam a reflexão difusa, diminuindo o brilho, que depende do tamanho, forma e concentração das partículas sobre a superfície do recobrimento [2,3].

A percepção de brilho inclui outros fatores [4]. Assim, ao observar dois objetos com características superficiais idênticas (mesma proporção de reflexão especular e difusa) a superfície mais escura parece ser mais brilhante. Também afeta a percepção do brilho o contraste entre a reflexão especular e difusa do entorno da superfície considerada. Hunter [5] identificou seis tipos de percepção de brilho. Entre eles está o brilho por contraste, que se deve ao contraste entre a fração da radiação refletida especularmente e difusamente da superfície considerada e de seu entorno.

Esta percepção de brilho pelo observador é buscada neste estudo ao aplicar, por jato, a tinta que daria um acabamento brilhante em alguns pontos, com boa percentagem de reflexão difusa (vidrado mate).

\section{Experimental}

Foi estudado o brilho dos vidrados resultantes ao se aplicar, por jato de tinta, várias espessuras de uma tinta de efeito brilhante sobre cinco esmaltes mate com diferentes composições: três para peças de grés porcelânico (M1 a M3) e duas para peças de azulejos de massa vermelha (M4 e M5). Em ambos os casos as referências atribuídas aos vidrados foram o esmalte base mate seguido de um traço e um número crescente ao se aumentar a quantidade de tinta aplicada. A correspondência entre as referências e os $\mathrm{g} / \mathrm{cm}^{3}$ de tinta aplicada são detalhados na Tabela 1 para a base M1. Para as bases restantes a correspondência é idêntica.

Estas quantidades de tinta aplicada, tendo-se em conta um teor de sólidos de $50 \%$ e uma densidade do vidro fundido de aproximadamente $2,6 \mathrm{~g} / \mathrm{cm}^{3}$, corresponderiam a uma espessura de camada de $2,6 \mu \mathrm{m}$ para cada $13,3 \mathrm{~g} / \mathrm{m}^{2}$. Assim, quando fossem aplicados $79,8 \mathrm{~g} / \mathrm{m}^{2}$ de tinta seria obtida uma camada de aproximadamente $16 \mu \mathrm{m}$ de espessura após a queima.

As peças de azulejo e de grés porcelânico foram queimadas em fornos industriais com ciclo térmico correspondente. Foi medido o brilho dos vidrados com um brilhômetro Novo Gloss da Rhopoint a um ângulo de $60^{\circ}$. Foram preparadas seções transversais polidas dos vidrados, que foram observadas, fotografadas e analisadas com sinal de elétrons retroespalhados de um microscópio eletrônico de varredura. As fotografias foram tratadas com o aplicativo de análise de imagem MicroImage 4.0 para determinar a espessura do vidrado de interação entre a tinta e as bases, que foi calculada como média de 10 medidas. Foi determinado o valor médio a partir da área de seção transversal sem fases cristalinas nas imediações da superfície vidrada. 
Tabela 1. Denominação dos vidrados obtidos com M1 em função da base e da quantidade de tinta aplicada

\begin{tabular}{cccccccc}
\hline Referência & M1-0 & M1-1 & M1-2 & M1-3 & M1-4 & M1-5 & M1-6 \\
\hline Tinta aplicada $\left(\mathrm{g} / \mathrm{m}^{2}\right)$ & 0 & 13,3 & 26,6 & 39,9 & 53,2 & 66,5 & 79,8 \\
\hline
\end{tabular}

\section{Resultados}

\subsection{Evolução do brilho dos vidrados com a quantidade de tinta aplicada}

A Figura 1 mostra a evolução do brilho das peças esmaltadas com as bases de esmalte porcelânico (M1 a M3) e de azulejo de massa vermelha (M4 e M5) ao se variar a quantidade aplicada da tinta digital (jato de tinta). Pode-se observar que, embora os valores de brilho dos esmaltes base sem aplicação de tinta sejam muito similares (entre 12 e 17) a tendência em cada peça é diferente; foram desenhadas as linhas que unem os pontos das séries para facilitar a observação dos dados.

O brilho das peças M1 a M3 se aproxima de um valor limite à medida que aumenta a quantidade de tinta, com um brilho máximo que parece ser muito similar para as três peças. M4 e M5 também mostram um mesmo valor de brilho para a aplicação de $66,5 \mathrm{~g} / \mathrm{m}^{2}$ de tinta, mas muito menor que no caso dos três esmaltes base anteriores.

\subsection{Peças de grés porcelânico: Vidrados obtidos com as bases $\mathrm{M} 1$ a $\mathrm{M} 3$}

\subsubsection{Microestrutura dos esmaltes originais}

A seção transversal da microestrutura original dos vidrados é mostrada na Figura 2. M1 é um vidrado mate de bário onde os cristais majoritários, que proporcionam a textura mate, são aluminossilicatos de bário, mostrados na figura como SiAlBa. Além disto, o vidrado contém silicato de zircônio (ZS) e alumina (A) adicionados, e óxido de zircônio (ZO) devitrificado pela dissolução parcial do ZS em um fundido pobre em sílica.

$\mathrm{O}$ vidrado M2 é um mate de cálcio que contém anortita devitrificada e silicato de zircônio adicionado, mostrados na figura, respectivamente, como An e ZS. O vidrado M3 é um mate com zinco e bário e as fases cristalinas identificadas foram aluminossilicato de bário (SiAlBa), em menor proporção que em M1, e o silicato de zircônio (ZS) e alumina (A) adicionados.

\subsubsection{Microestrutura das peças com aplicações de tinta sobre os esmaltes base}

As Figuras 3 a 5 mostram como varia a microestrutura das peças vidradas de grés porcelânico à medida que aumenta a quantidade de tinta aplicada sobre os três esmaltes base ensaiados. No caso do M1 observa-se que, à medida que aumenta a quantidade de tinta aplicada, a parte superior da peça passa a ser um vidro homogêneo. A interação entre a tinta e o esmalte base é muito significativa em M1-2, onde são observadas partículas de alumina e de silicato de zircônio provenientes da base M1 na superfície da peça, indicando que a tinta foi introduzida até o interior da base e se integrou com ela.

Na parte direita da micrografia a presença de tinta é mais evidente, pois aumentou a proporção de vidro

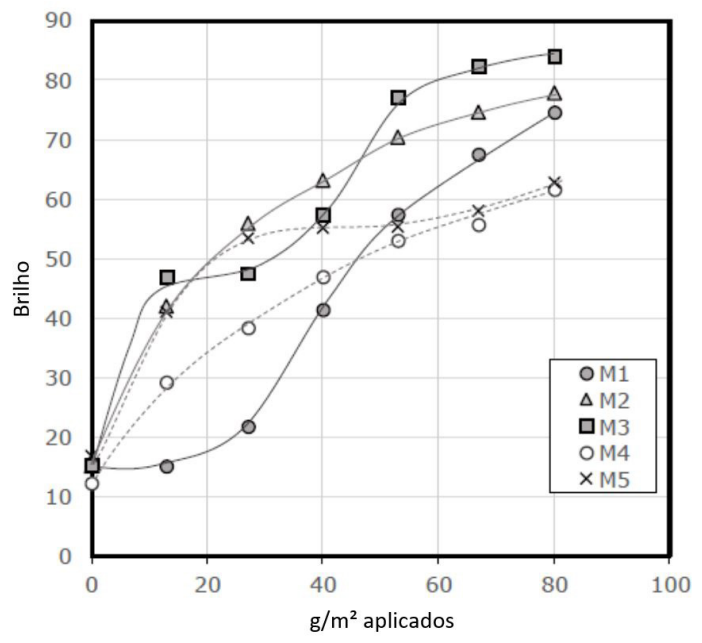

Figura 1. Evolução do brilho das peças esmaltadas com bases porcelânicas (M1 a M3) e de massa vermelha (M4 e M5) ao variar a quantidade aplicada de tinta digital. Os pontos foram unidos com linhas para facilitar sua observação

e desapareceram muitos dos aluminossilicatos de bário da base M1. De qualquer forma, a espessura da tinta da peça M1-2 é muito pequena, muito menor que a das peças M1-4 e M1-6, o que justificaria o aumento do brilho comparativamente pequeno que se produz ao se aplicar $26,6 \mathrm{~g} / \mathrm{m}^{2}$ de tinta sobre o esmalte base M1 (Figura 1).

$\mathrm{O}$ aspecto das peças intermediárias da série M1 (M1-3 e M1-5), não incluídas na figura, também é muito similar. A zona de interação poderia ser definida como aquela na qual desapareceram os aluminossilicatos de bário da base M1. Para facilitar a identificação da zona de interação, na Figura 6 foi marcado o contorno desta zona no vidrado M1-5, desenhada manualmente para determinar sua espessura por análise de imagem. Deve-se ressaltar, em todos os casos, a variabilidade da espessura da zona de interação dentro de uma mesma micrografia.

Nas peças da série M2 observa-se um comportamento similar. Neste caso, a interação entre a tinta e a base conduz à desaparição dos cristais de anortita da base M2. As partículas de silicato de zircônio da base M2 (zonas com o nível de cinza mais claro) podem ser utilizadas como marcadores onde acabaria a aplicação da tinta e começaria a base M2, mas pode-se observar que a zona de interação encontra-se debaixo das partículas de silicato de zircônio, zona sem anortita, indicando que a tinta fundiu-se em uma maior profundidade.

Segundo estes critérios, as zonas de interação de M2-2 e M2-4 são maiores que as de M1-2 e M1-4, respectivamente, embora a zona de interação das peças com a máxima quantidade aplicada (M1-6 e M2-6) seria 

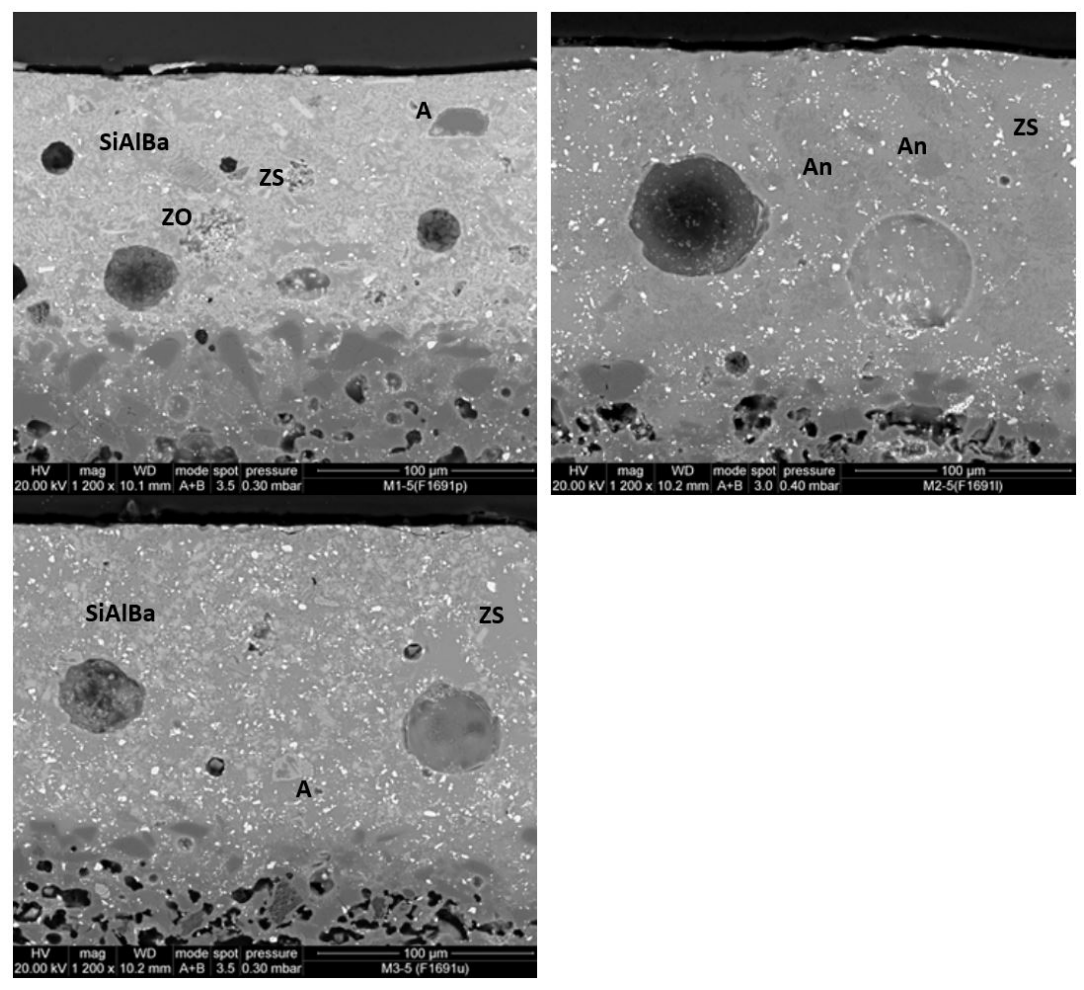

Figura 2. Seção transversal das bases M1 a M3 sem aplicação da tinta. SiAlBa: aluminossilicato de bário; ZS: silicato de zircônio; A: alumina; ZO: óxido de zircônio; An: anortita
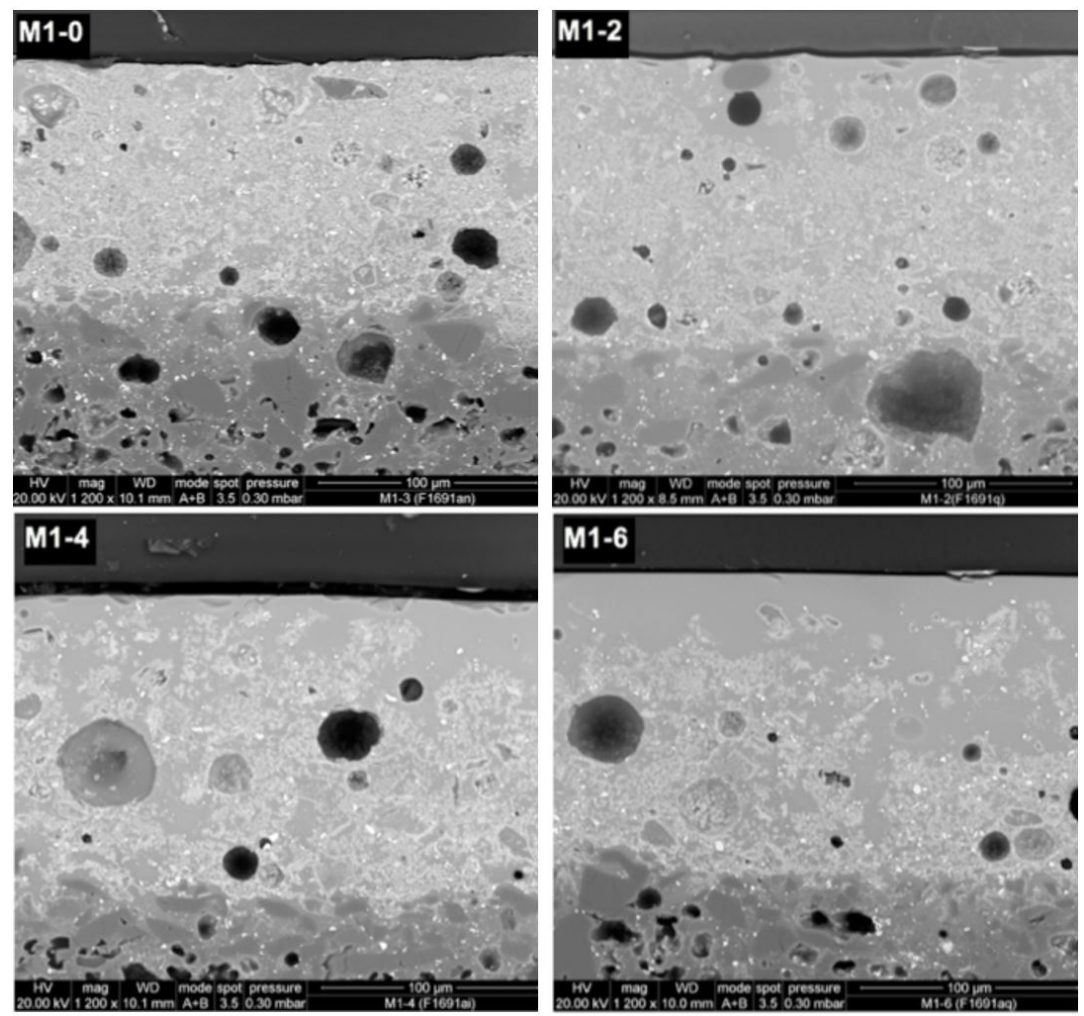

Figura 3. Seção transversal do vidrado M1 sem aplicação (M1-0) com gramatura variada de tinta. $1200 \times$ 

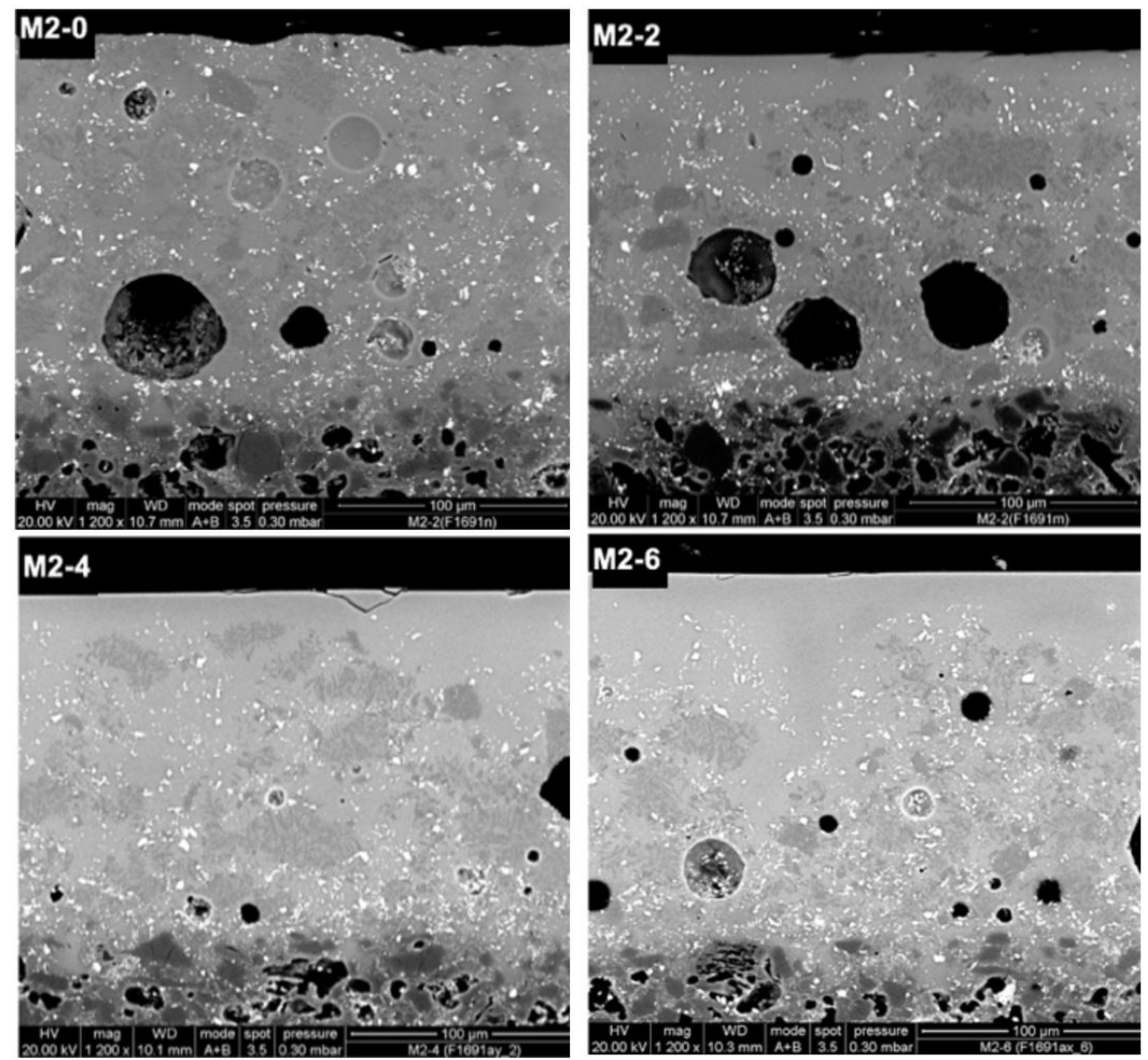

Figura 4. Seção transversal do vidrado M2 sem aplicação (M2-0) com gramatura variada de tinta. $1200 \times$

da mesma ordem. Na Figura 6 é incluído, também, como exemplo, o contorno da zona de interação para a peça M2-5.

As peças obtidas com M3 são mostradas na Figura 5. Como a curva de evolução de brilho de M3 é peculiar, foram incluídas aqui micrografias de todas as aplicações. Pode-se observar como o silicato de zircônio, proveniente da base M3, encontra-se muito acima do que seria a zona de interação entre a base e a tinta, que poderia ser definida como aquela na qual desapareceram os cristais de aluminossilicato de $\mathrm{Ba} / \mathrm{Zn}$, responsáveis pela textura mate de M3. Se a zona de interação for definida desta forma, observa-se que M3-1 e M3-2 têm praticamente a mesma espessura de interação e, portanto, brilhos muito similares (Figura 1). Esta espessura de interação depois aumenta e passa a ser muito similar para M3-5 e M3-6 que, de novo, apresentam valores de brilho muito próximos entre si.

Assim, foi deduzido que poderia haver uma relação entre a espessura da zona de interação e o brilho obtido na peça vidrada. Se $o$ aspecto mate era dado, respectivamente, pelas fases cristalinas de aluminossilicato de bário e anortita (cristais de grande tamanho), era razoável pensar que o brilho poderia ser função da espessura das zonas de interação onde se produz a dissolução destas fases. Por tanto, decidiu-se medir a espessura das zonas de interação, delimitando manualmente o contorno destas zonas, determinando suas áreas por análise de imagem e calculando sua espessura média ao dividir-se tal área pelo comprimento do objeto em $\mu \mathrm{m}$. Em cada peça era medida a espessura média em 10 imagens e calculava-se o resultado final como média destas 10 medidas.

Na Figura 6 é mostrada a área de interação para duas micrografias das amostras M1-5 e M2-5.

As espessuras medidas são representadas em função da quantidade de tinta aplicada, na Figura 7(a). Observa-se que as curvas traçadas unindo-se os pontos apresentam a mesma tendência que as curvas de evolução de brilho com a quantidade de tinta aplicada, mostradas na Figura 1. Conclui-se que pode existir uma relação praticamente linear entre o brilho das peças e a espessura da camada de interação da tinta com a base.

A linha reta descontínua representa a espessura aproximada que deveria ter a aplicação de tinta em função da gramatura depositada, tendo-se em conta um teor de sólidos de $50 \%$ em massa, uma densidade de $2,6 \mathrm{~g} / \mathrm{cm}^{3}$ para o sólido fundido e ausência de porosidade na camada. Observa-se que as espessuras das camadas de interação são muito maiores que a correspondente à espessura da tinta aplicada, com exceção para a amostra M1-2, cuja espessura de camada de interação é menor, indicando que para esta gramatura pequena predominou o caráter da base M1 sobre a da tinta. 


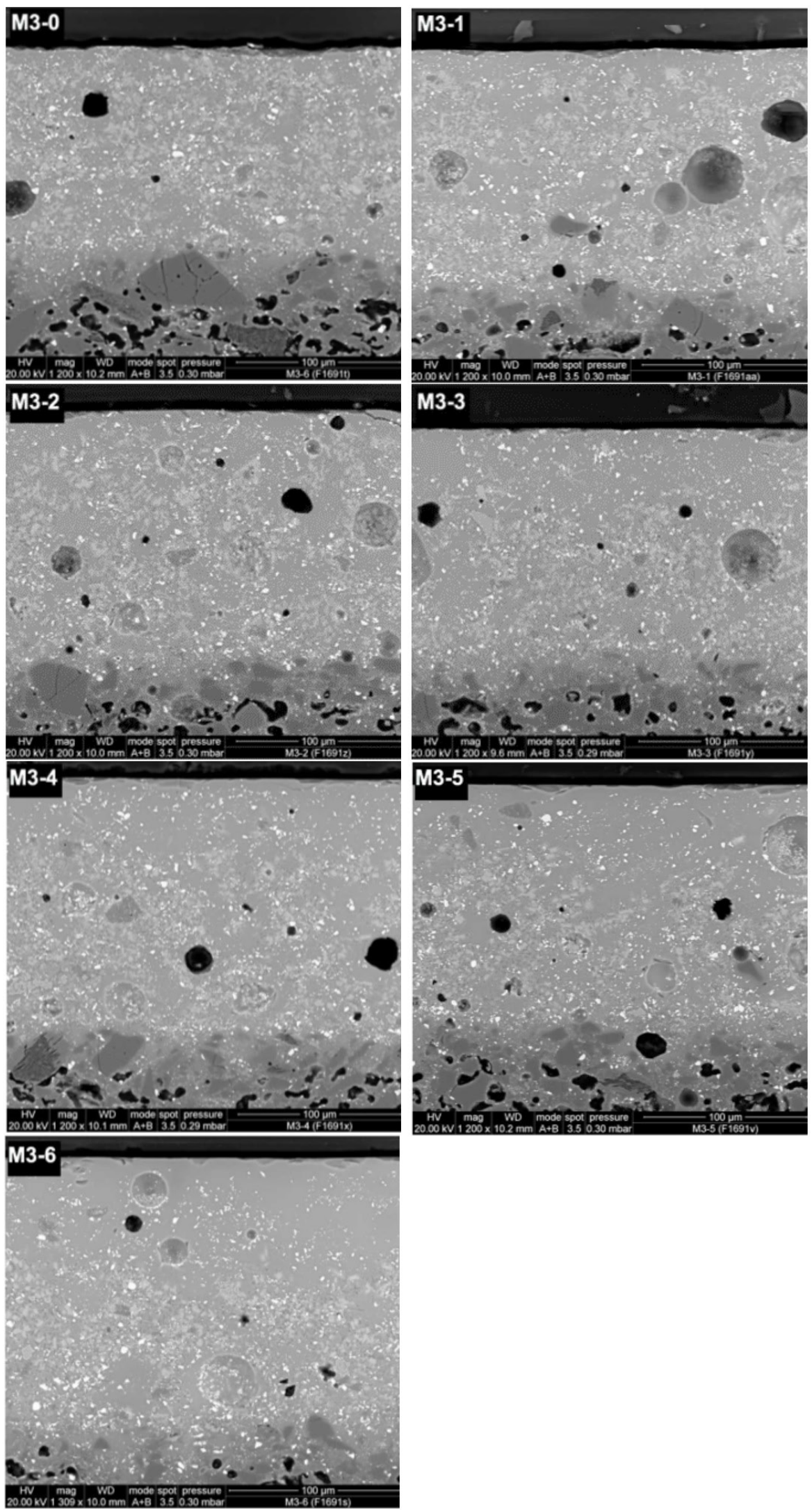

Figura 5. Seção transversal do vidrado M3 sem aplicação (M3-0) com gramatura variada de tinta. $1200 \times$ 

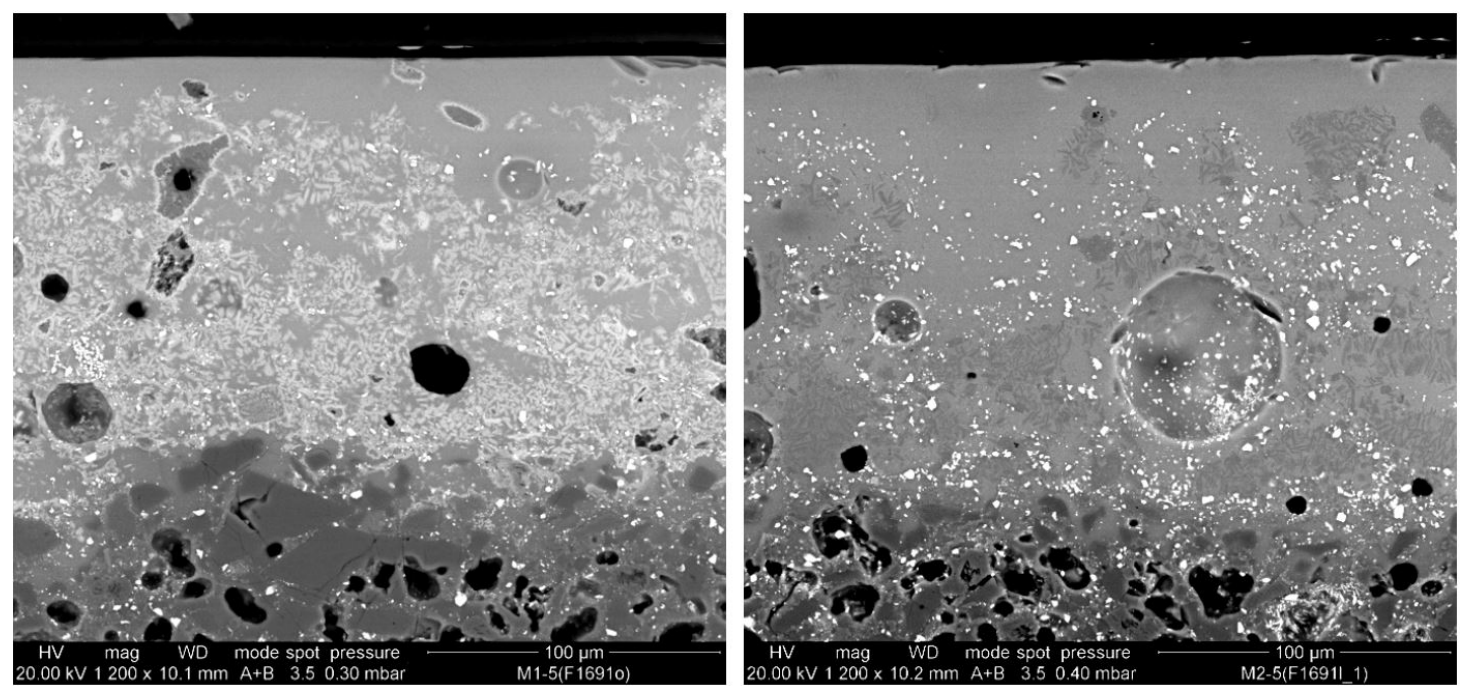

Figura 6. Exemplo de seleção da zona de interação em duas micrografias, correspondentes às peças M1-5 e M2-5
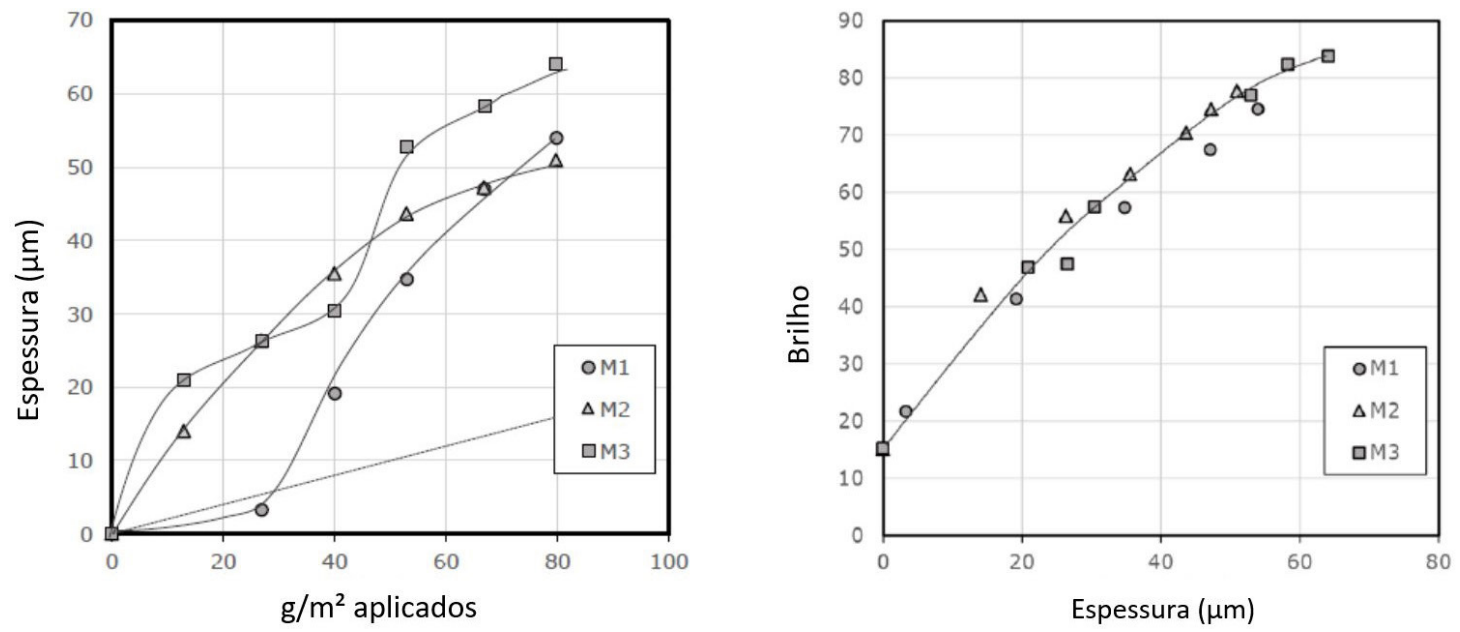

Figura 7. (a) Espessura da camada de interação do esmalte base com a tinta em função da quantidade de tinta aplicada para as três bases de grés porcelânico. As curvas foram traçadas para facilitar a visualização dos pontos experimentais. A linha reta descontínua indica qual deveria ser a espessura aproximada da camada de tinta aplicada. (b) Variação de brilho com a espessura da camada de interação

\subsubsection{Relação entre o brilho e a espessura da camada de interação}

A evolução do brilho em função da espessura da camada de interação é representada na Figura 7(b). Vê-se uma tendência muito similar para todas as peças obtidas com as bases M1 e M3, embora o brilho obtido com a base M1 seja um pouco inferior. Estes resultados confirmam que, para estas peças nas quais a natureza da camada de interação parece muito similar, pois é um vidro homogêneo, o brilho é determinado pela espessura da camada de interação.

\subsection{Peças de azulejo de massa vermelha: Vidrados obtidos com as bases M4 e M5}

O vidrado M4 é um mate de cálcio e bário que devitrifica aluminossilicatos de bário em pequena proporção, com adição de alumina, nefelina, silicato de zircônio e quartzo.
M5 é um mate de bário e zinco com adição de quartzo, nefelina, alumina e silicato de zircônio. Seu aspecto pode ser observado nas Figuras 8 e 9 (vidrados M4-0 e M5-0, respectivamente).

Os vidrados base M4 e M5 diferenciam-se na proporção de cristais de aluminossilicato de bário devitrificados (maior em M5) e na composição da fase vítrea, que em M4 contém mais cálcio e em M5 mais zinco. Nas partículas de alumina do esmalte forma-se uma crosta de ganita $\left(\mathrm{ZnAl}_{2} \mathrm{O}_{4}\right)$ por interação com o fundido rico em zinco. Esta crosta protege a alumina e impede sua dissolução.

As Figuras 8 e 9 mostram a evolução microestrutural dos vidrados ao se incrementar a quantidade de tinta aplicada. Como nos casos interiores, a tinta origina zonas de interação que inibem a formação das fases responsáveis pelo efeito mate dos esmaltes base. Nestes vidrados 

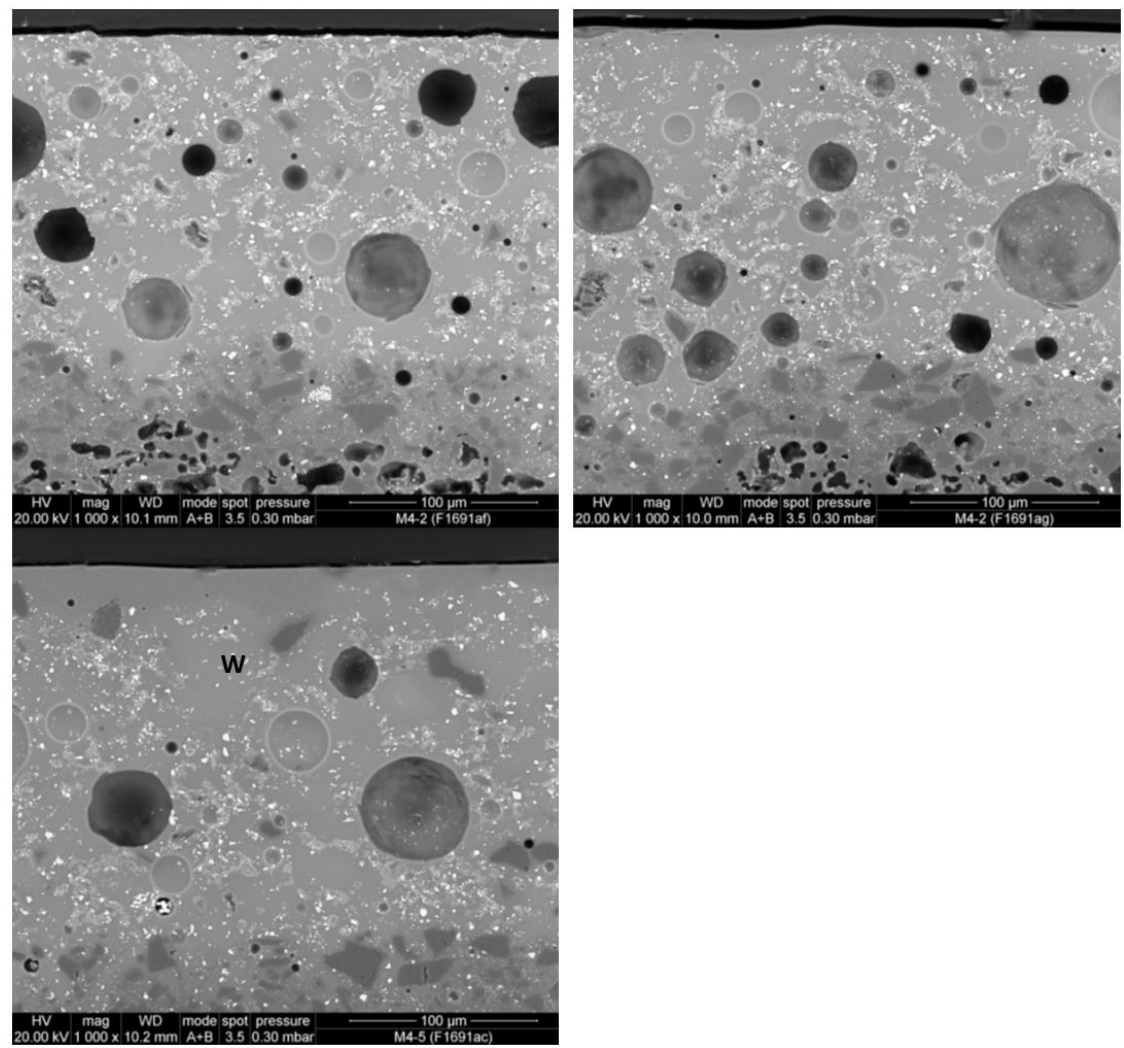

Figura 8. Seção transversal do vidrado M4 sem aplicação (M4-0) e com 26,6 e 66,5 g/m² de tinta (M4-2 e M4-5). 1000 ×. W: wollastonita
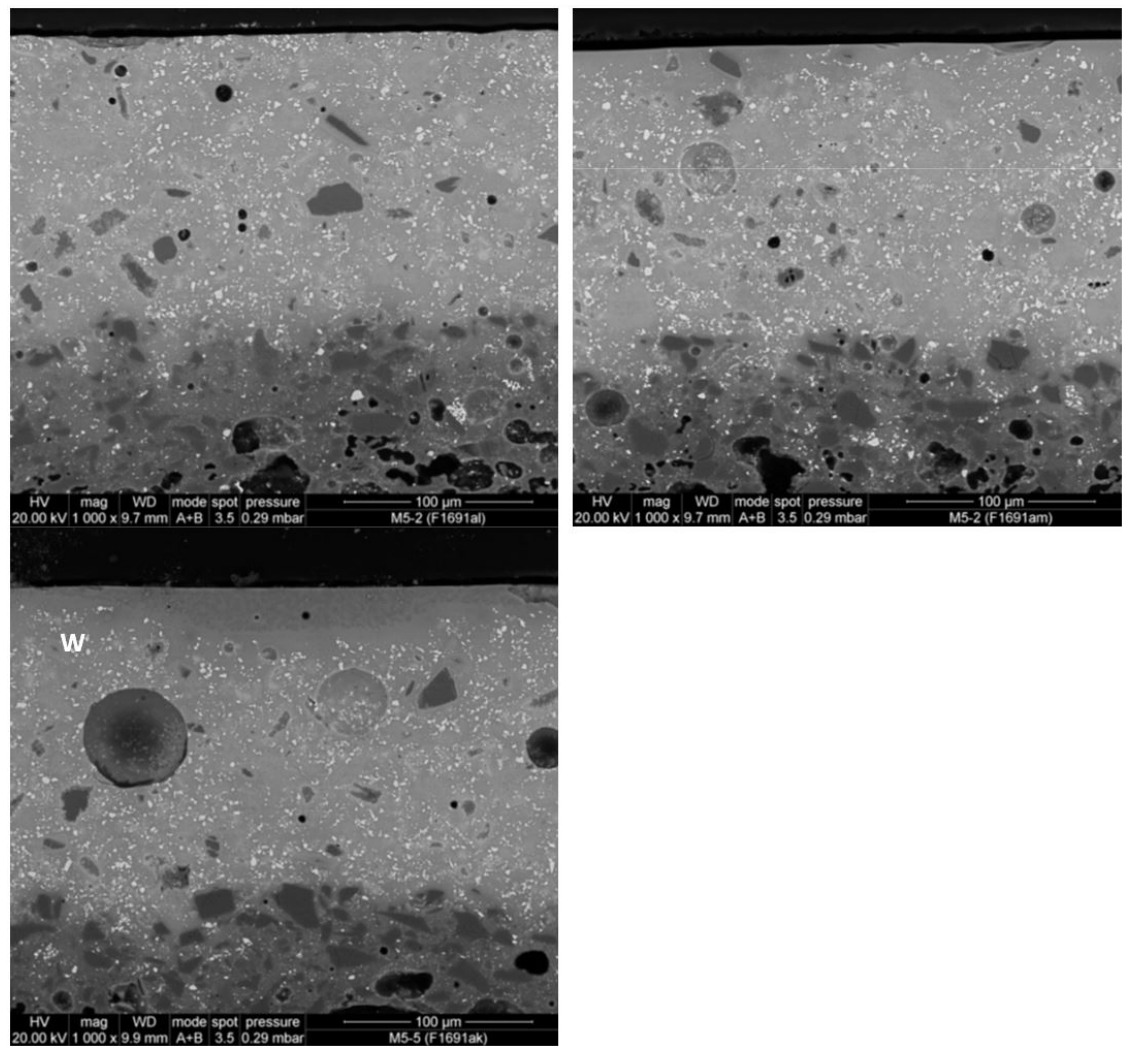

Figura 9. Seção transversal do vidrado M5 sem aplicação (M5-0) e com 26,6 e 66,5 g/m² de tinta (M4-2 e M4-5). 1000 ×. W: wollastonita 


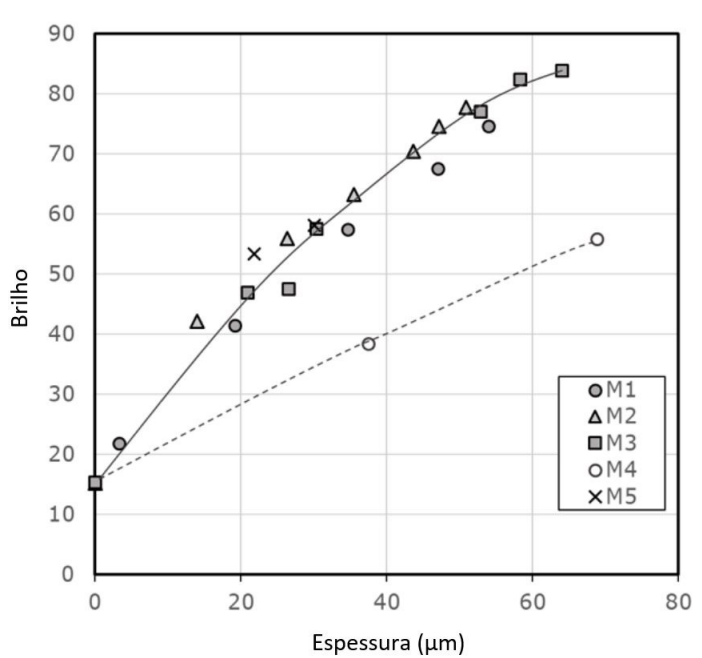

Figura 10. Evolução do brilho de todas as peças esmaltadas com a espessura da camada de interação. Os pontos foram unidos com linhas para facilitar sua observação

foram observadas somente peças com aplicação de tinta de 26,6 e $66,5 \mathrm{~g} / \mathrm{m}^{2}$.

Observa-se que a espessura da zona de interação da tinta com o esmalte M4 é muito maior que com o vidrado M5, com o qual parece ter reagido menos. Isto pode ter sido devido à natureza de $\mathrm{M} 4$, que contém mais fase vítrea e menos cristais devitrificados que M5.

Deve-se destacar que, tanto para o caso de M4-2 e M4-5 como de M5-5, a tinta não gera um vidro homogêneo na superfície da peça, pois há wollastonita devitrificada, como se pode ver na Figura 8 para M4-5 e na Figura 9 para o caso de M5-5.

A Figura 10 mostra o brilho das peças obtidas com as bases M4 e M5 em função da espessura de interação. São incluídos os valores de brilho das bases anteriores.

Observa-se que todas as bases, com exceção de M4, formam uma mesma linha de tendência e o brilho de M4 é muito menor ao que corresponderia a sua espessura de interação, que é considerável. Estes resultados poderiam estar relacionados com a desvitrificação de wollastonita na superfície do vidrado. Esta fase, característica dos esmaltes de cálcio tradicionais, forma cristais de grande tamanho. Sua presença na superfície externa do vidrado predomina sobre a influência da camada de interação, que permanece abaixo, de forma que M4-5 e M5-5 (ambos com wollastonita superficial) têm um mesmo valor de brilho, apesar da disparidade de tamanho de suas zonas de interação.

\section{Conclusões}

A tinta brilho se comporta de forma diferente quando utilizada para produtos de grés porcelânico ou para azulejos de massa vermelha. No caso do grés porcelânico, a tinta cria zonas de interação onde são eliminadas as fases que devitrificam no vidrado base e que dão seu aspecto mate. Nas peças de grés porcelânico não ocorre desvitrificação de fases cristalinas na camada de interação e parece haver uma correlação direta entre a espessura da camada de interação e o aumento do brilho.

Para uma gramatura de $40 \mathrm{~g} / \mathrm{m}^{2}$, considerando a média estudada, a base M2, mate de cálcio, é a que apresenta o maior valor de brilho e de camada de interação. Entre as bases estudadas esta é a estrutura que mais favorece a formação de camada vítrea para esta gramatura. Para maiores gramaturas de aplicação observa-se que o brilho aumenta gradativamente a um valor máximo próximo a 84 .

A espessura da camada de interação é sempre maior que aquela que corresponderia a cada uma das aplicações de tinta, com exceção para os casos das amostras M1-1 e M1-2, onde a espessura das camadas de interação é menor que a teórica. Isto pode ser devido a que M1 é um mate de bário com grande tendência a formar cristais, requerendo maior quantidade de tinta brilhante para inibir a cristalização e assim formar uma maior camada vítrea de interação. Como consequência, tanto M1-1 quanto M1-2 têm um valor de brilho muito baixo comparado com os outros mates aos quais se aplicou a mesma quantidade de tinta. Destaca-se que na representação do brilho em relação à zona de interação estes vidrados estão sobre a linha de tendência.

Para o caso de azulejo de massa vermelha, há uma grande diferença nas zonas de interação com a tinta. O brilho destes vidrados é afetado pela presença de cristais de wollastonita na superfície. A presença destes cristais atenua o brilho das peças, que é menor que o que corresponderia ao da zona de interação.

\section{Referências}

[1] Sanz, V. Avances en la tecnología de decoración digital de baldosas cerámicas. QUALICER. XIV Congreso Mundial de la Calidad del Azulejo y del Pavimento Cerámico. Castellón, 2016.

[2] Farrier, L.M., Influence of surface roughness on the specular reflectance of low gloss coatings using bidirectional reflectance measurements. Technical Memo. Air Force Research Lab Wright-Patterson AFB OH Materials and Manufacturing Directorate, OH (USA). 2006. http://www.dtic.mil/get-trdoc/ pdf?AD=ADA464906

[3] JJärnström, J.; Ihalainen, P.; Backfolk, K.; Peltonen, J. Roughness of pigment coatings and its influence on gloss. Applied Surface Science, 254, 5741-5749, 2008.

[4] Chadwick, A.C.; Kentridge, R.W. The perception of gloss: A review. Vision Research 109, 221-235, 2015.

[5] Hunter, R. S. Methods of determining gloss. Journal of Research of the National Bureau of Standards, 18 (1), 19-41, 1937. 